\title{
EXPLORING THE IMPLICATIONS OF GENDER IDENTIFICATION FOR TRANSGENDER PEOPLE UNDER AUSTRALIAN LAW
}

\author{
Ashleigh Bagshaw.
}

Developments in Australian law over the last 40 years have allowed transgender persons a greater level of autonomy when it comes to establishing their legal gender. The shift in some jurisdictions from employing a strict biologically-based test for determining gender identity to adopting a multifactorial approach based on a broad range of relevant factors has enabled a greater number of individuals to gain legal recognition of their preferred gender. This article traces the development of a gender identification test at common law. It explores Australian federal and state legislative schemes and draws attention to the inconsistencies between jurisdictions. It also highlights the impact that these statutory variations may have upon transgender individuals. Parts I, II and III discuss the current approach to regulating gender identity at common law and via legislation. Part IV discusses the impact of these laws on transgender people and highlights the need for all Australian jurisdictions to adopt a uniform approach to gender identification.

\section{CONTENTS}

Introduction

II Gender Identification at the Federal Level

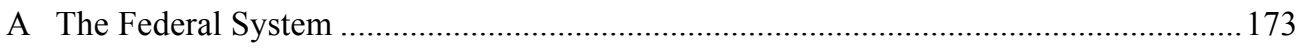

B Distinguishing between Sex and Gender ................................................................. 174

C Implications of the Australian Guidelines .................................................................. 174

D The Federal Position: Re Kevin .................................................................................. 175

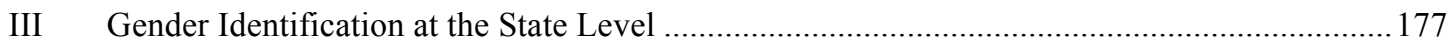

IV The Repercussions for Transgender People ..................................................................... 179

A Inconsistencies between State and Federal Laws ................................................... 179

B Potential Implications in Relation to Same-Sex Marriage ............................................ 181

C The New Zealand Position - A Solution to the Dilemma? ........................................... 181

LLB student, School of Law, University of South Australia. 


\section{INTRODUCTION}

There has been a dramatic shift in laws relating to gender identification, which has led to a rejection of the traditional biological tests that were established under early case law. The common law is now defined by a multifactorial approach, which was established in the cases of Re Kevin: Validity of Marriage of Transsexual ('Re Kevin'), Attorney-General (Cth) $v$ "Kevin and Jennifer" ('Re Kevin Appeal') ${ }^{1}$ and $A B v$ State of Western Australia; AH v Western Australia ('AB v Western Australia'). ${ }^{2}$ While this approach is endorsed at both the federal level and in the States of Western Australia and South Australia, the legislation in other jurisdictions retains a biological approach that is based on requirements for sex reassignment surgery. These variations between jurisdictions create significant repercussions in relation to same-sex marriage and may potentially undermine laws regulating marriage at the federal level. This article explores these themes by discussing the current laws regulating transgender identity in Australia, both at common law and through legislative schemes. More specifically, the article identifies how the differing approaches between jurisdictions affect marriage laws in Australia. Part I explores the legal history of this area and the emergence of a gender identification test from English and Australian case law. Parts II and III discuss the regulation of gender identity at both the federal and state level in Australia. Finally, Part IV discusses the impact of current laws on transgender persons.

\section{Historical Background: A Purely Biological TeST}

Gender identification of transgender persons is a contentious area with a complex history at common law. The test for determining gender initially focused solely on biological factors. In the 1971 English case of Corbett $v$ Corbett ('Corbett') ${ }^{3}$ it was determined that the law should use three biological criteria to determine sex: chromosomal, gonadal and genital. In accordance with this test, it could be disputed whether a hermaphrodite born

\footnotetext{
The decision of Chisholm J at first instance (2001) 165 FLR 404 ('Re Kevin') was approved and cited extensively by the Full Court of the Family Court in the subsequent appeal Attorney-General (Cth) v "Kevin and Jennifer" (2003) 172 FLR 300 ('Re Kevin Appeal'). 
with both ovaries and female chromosomes was actually a woman, because the individual concerned would not satisfy the requirement of having only female genitals. The bluntness of this purely biological approach as an instrument for determining gender was found to be inadequate and this test was abandoned in the 1988 case of $R v$ Harris and McGuinness. ${ }^{4}$ This New South Wales case decided that while the biological criteria that were applied in Corbett ${ }^{5}$ were to be considered, they should not constitute the only means of determining gender. This case introduced a test based upon psychological self-identification, which, when considered alongside biological factors, would determine the sex identity of a transgender person. While psychological sex identification was an important factor, it was held to be insufficient in itself for legal recognition to be granted. ${ }^{6}$ Justice Mathews reasoned that adopting a purely psychological approach as the basis for achieving legal recognition would create 'enormous difficulties of proof'; would leave the system 'vulnerable to abuse by people who were not true transsexuals'; and potentially 'lead to a trivialisation of the difficulties genuinely faced by people with identification disharmony'. ${ }^{7}$ In Re Kevin in 2001 and the subsequent appeal decision in $2003,{ }^{8}$ a multifactorial approach to determining sexual identity was established that took biological, psychological and social considerations into account.

This approach was ultimately endorsed by the High Court in 2011 in the case of $A B v$ Western Australia, ${ }^{9}$ which concerned the gender of two individuals as determined under the Gender Reassignment Act 2000 (WA). The two appellants were 'transmen', ${ }^{10}$ who had 'each identified as male from an early age and [were] diagnosed as suffering from a gender identity disorder, or gender dysphoria'. ${ }^{11}$ While both appellants had undergone some surgical intervention in the form of having their breasts removed and receiving testosterone therapy, neither had undergone a phalloplasty procedure. In

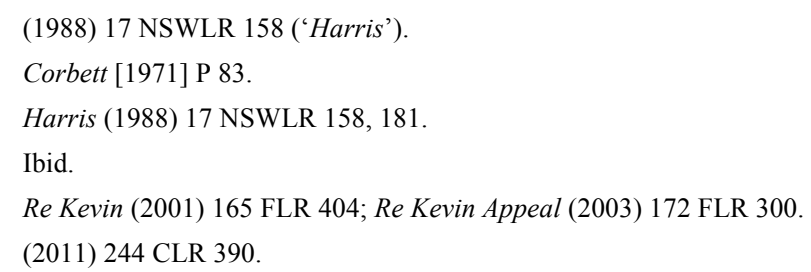

10 As defined by Theodore Bennett in 'Transsexualism and the Consideration of Social Factors Within Sex Identification Law' (2013) 35 (2) Adelaide Law Review 379, fn 2: a 'transman' is the term for a transgender person who was born biologically female but self-identifies as a male. In contrast, a 'transwoman' is a person born biologically male but who self-identifies as a female.

${ }^{11}$ AB v Western Australia (2011) 244 CLR 390, 399 [14] (French CJ, Gummow, Hayne, Kiefel and Bell JJ). 
addition, neither contemplated any further surgery such as a hysterectomy. The appellants had applied to the Western Australian Gender Reassignment Board for a certificate recognising their sex identity as male. However, this recognition was refused on the grounds that both appellants retained female reproductive systems that were found to be 'inconsistent with being male, and therefore inconsistent with being identified as male'. ${ }^{12}$

The High Court decided that placing an emphasis on biological factors in determining the sex of a person was insufficient and instead endorsed a multifactorial approach. While it was held that some surgical intervention was required, the Court decided that the legislation did not 'require that the person undertake every procedure to remove every vestige of the gender which the person denies, including all sexual organs' ${ }^{13}$ The Court held that other factors should also be considered, including a person's psychological perception of themself and the social recognition of that person as a particular gender. This outcome was considered to be positive in the sense that it "stands as authority for "beneficial" legislation, which promotes or empowers human rights, to be given a broad, fair and liberal interpretation' ${ }^{14}$ It also adheres to the complex psychological considerations of sex identity, which should be a key consideration in determining gender. Studies suggest that 'many transsexual, transgender, and gender-nonconforming individuals find comfort with their gender identity, role, and expression without surgery'. ${ }^{15}$ Further, the decision suggests that sex should be interpreted fluidly when determining the legal sex identity of a transgender person. As Olivia Rundle explains:

The words 'the sex of a person is not, and a person's gender characteristics are not, in every case unequivocally male or female' constitute a powerful declaration by the High Court about the reality that sex and gender are not a two option dichotomy where every person is exclusively male or female. The acceptance of the High Court of this approach to sex and gender may have

$12 \operatorname{Ibid} 389$ [12].

13 Ibid 405 [33].

14 Jessica Berry, 'Case Comment: AB v Western Australia; AHv Western Australia (2001) 244 CLR 390' (2012) 19(1) Murdoch University Law Review 73, 77 citing Lee Carnie, 'High Court Affirms Right to Gender Identity and Expression' Human Rights Law Centre, $<$ http://www.hrlc.org.au/jurisdiction/australia/b-v-western-australia-2011-hca-42-6-october2011/>.

15 Eli Coleman et al, 'Standards of Care for the Health of Transsexual, Transgender, and Gender-Nonconforming People, Version 7' (2011) 7 International Journal of Transgenderism 165, 199 citing J Joris Hage, and Refaat B Karim, 'Ought GIDNOS get nought? Treatment Options for Nontranssexual Gender Dysphoria' (2000) 105(3) Plastic and Reconstructive Surgery 1222. 
implications for intersex and transgender people in future legal cases where there is a need to define their sex (for example, for the purpose of marriage). ${ }^{16}$

The High Court's judgment in $A B v$ Western Australia is notable because it uses a liberal but careful interpretation of the test that should be applied in determining the identity of a transgender person. The decision supports the view that surgery to fully remove and construct genitals is not required in order for community members to identify a person as a man or woman in their daily lives. ${ }^{17}$ This view contrasts with the dictionary definitions of the male and female gender and perceived community standards, which focus upon genitals and reproductive organs. It also conflicts with statutory gender or sex recognition regimes in most Australian territories and states (other than South Australia and Western Australia) which provide for legal recognition of a person's gender only after they have undergone surgery to alter their reproductive organs.

\section{GENDER IdENTIFICATION AT THE FEDERAL LEVEL}

\section{A The Federal System}

Under the Australian Constitution, legislative powers are divided between a central Commonwealth Government and the six states. The Australian Constitution recognises the continuing powers of state parliaments to pass laws on any topic other than those areas of power granted exclusively to the Commonwealth under ss 51 and 52 of the Constitution or otherwise limited by the Constitution. Areas regulated by federal legislation include marriage ${ }^{18}$ and external affairs, ${ }^{19}$ whereas such matters as education, community services and health, form the legislative prerogative of the states.

These two levels of government are usually independent of each other. However, while the states are granted autonomy to legislate independently of the Commonwealth, it is essential that consistency is maintained between state and Commonwealth laws. Under current legislative schemes, the gender identity of a person can be determined differently by the two different levels

\footnotetext{
Jessica Berry, 'Case Comment: ABv Western Australia; AHv Western Australia (2001) 244 CLR 390' (2012) 19(1) Murdoch University Law Review 73, 77 citing Olivia Rundle, 'High Court Interprets WA Provisions for Legal Recognition of Reassigned Gender' Australian Health Law Bulletin 2 (2012) 182 [184].

17 ABv Western Australia (2011) 244 CLR 39090, 401 [32].

8 Australian Constitution s 51(xxi).

19 Ibid s 51(xxix).
} 
of government, mainly because many states have not adopted the multifactorial approach endorsed at the Commonwealth level. Consequently, the current system of gender identification in Australia, taken as a whole, does not appear to uphold principles of fairness and equal treatment. The consequences of a different approach being taken to gender determination at these two levels of government may lead to inconsistencies in the way that an individual is treated before the law. This is particularly problematic in relation to marriage law, which is explored in greater depth in Part IV.

\section{B Distinguishing between Sex and Gender}

Lee Carnie from the Human Rights Law Centre noted in response to the case of $A B v$ Western Australia, ${ }^{20}$ that 'flexible understandings are required to grapple with the way that sex and gender are often assumed as unequivocal, in order to adequately respect the rights of transgender people'. ${ }^{21}$ The Australian Government collects and uses information based on gender, rather than sex, and has incorporated these fluid notions into the 2013 Australian Government Sex and Gender Recognition Guidelines ('Australian Guidelines'), ${ }^{22}$ which recognise the identity of individuals who identify as a gender other than the gender they were assigned at birth. The Australian Guidelines draw a clear distinction between the concepts of sex and gender and explain that sex 'refers to the chromosomal, gonadal and anatomical characteristics associated with biological sex', ${ }^{23}$ whereas gender 'is part of a person's personal and social identity. ${ }^{24}$

\section{Implications of the Australian Government Sex and Gender Recognition Guidelines}

The Australian Guidelines are used by all Commonwealth departments and agencies and apply to all areas regulated by Commonwealth legislation, including social security, passports and medical records. While the Australian Guidelines encourage individuals to ensure that their documents reflect their preferred gender, they note that information about a person's biological sex may be required where there is a legitimate need for it; for

20 Ibid

${ }^{21} \quad$ Lee Carnie, High Court Affirms Right to Gender Identity and Expression (6 October 2011) Human Rights Law Centre <http://hrlc.org.au/high-court-affirms-right-to-gender-identityand-expression/>.

22 Commonwealth of Australia, Australian Government Guidelines on the Recognition of Sex and Gender (2013) ('Australian Guidelines').

23 Ibid 3 [11].

24 Ibid 3 [13]. 
example, where a service or benefit is directly related to biological sex. ${ }^{25}$ Under the Australian Guidelines, biological factors are not taken into consideration when determining the identity of a transgender person, and surgical intervention such as 'sex reassignment surgery and/or hormone therapy are not pre-requisites for the recognition of a change of gender in Australian Government records'. ${ }^{26}$

Australian Commonwealth departments and agencies recognise the following documents as evidence: a statement from a registered medical practitioner or a registered psychologist; a valid Australian Government travel document, such as a passport, specifying the person's preferred gender, or; a State or Territory birth certificate or recognised details of a certificate showing a change of gender. ${ }^{27}$ Thus, a person may be recognised as another gender based purely on their psychological self-identification, providing this recognition is verified by a member of the medical profession. However, this recognition of a person's identity at the federal level does not necessarily coincide with the gender/sex identity recognised at the state level. As the Australian Guidelines do not apply to state and territory departments, transgender persons are often also subject to the highly restrictive tests present at the state level. Thus, while a transman may legally be recognised as a man at the federal level, and may even be determined to be male for the purposes of marriage, it is possible that this would not be reflected on his birth certificate because this certificate would be issued by a state body governed by state legislation.

\section{The Federal Position: Re Kevin}

The authority of Corbett was explicitly rejected in Australian law by the landmark case of Re Kevin. Chisholm J said:

I see no basis in legal principle or policy why Australian law should follow the decision in Corbett. To do so would, I think, create indefeasible inconsistencies between Australian marriage law and other Australian laws. It would take the law in a direction that is generally contrary to developments in other countries. It would perpetuate a view that flies in the face of current medical understanding and practice. Most of all, it would impose indefensible suffering on people who have already had more than their share of difficulty, with no benefit to society. ${ }^{28}$

\footnotetext{
Commonwealth of Australia, above n 22, 3.

6 Ibid 4.

27 Ibid.

28 Re Kevin (2001) 165 FLR 404, 474 [326]; Re Kevin Appeal (2003) 172 FLR 300, 312 [62].
} 
In stark contrast to Corbett ${ }^{29}$ Re Kevin was not classified as a case relating to the issue of same-sex marriage, despite having a similar factual matrix. ${ }^{30}$ In this case, the Court granted the application for a declaration of the validity of the marriage. The applicant, Kevin, had undergone partial sex reassignment surgery through the removal of his internal female organs, including his uterus and ovaries, but had not undertaken phalloplasty procedures. However, Chisholm J was satisfied that sufficient psychological and anatomical factors were present for Kevin to be legally identified as a male. Thus, this case marked a change in the common law, and the subsequent appeal, which affirmed the original decision, stands as authority for the adoption of a multifactorial approach to sex identification for the purposes of marriage law.

In coming to his conclusion, Chisholm J noted that:

To determine a person's sex for the purpose of the law of marriage, all relevant matters need to be considered ... [R]elevant matters include, in my opinion, the person's biological and physical characteristics at birth (including gonads, genitals and chromosomes); the person's life experiences, including the sex in which he or she is brought up and the person's attitude to it; the person's self-perception as a man or woman; the extent to which the person has functioned in society as a man or a woman; any hormonal, surgical or other medical sex reassignment treatments the person has undergone, and the consequences of such treatment; and the person's biological, psychological and physical characteristics at the time of the marriage, including (if they can be identified) any biological features of the person's brain that are associated with a particular sex. ${ }^{31}$

The Commonwealth Attorney-General appealed, and argued that a strictly biological test should be applied and that the gender of a person should be determined by the individual's chromosomes, gonads and genitals at birth. It was also argued that additional factors, including the way that individuals perceive themselves and the social acceptance of a person's sex, should not be taken into consideration. The Attorney-General further contended that the ordinary meaning of man for the purpose of the Marriage Act 1961 (Cth) should not be interpreted as including a post-operative female to male transsexual. However, this appeal was dismissed by the Full Court of the

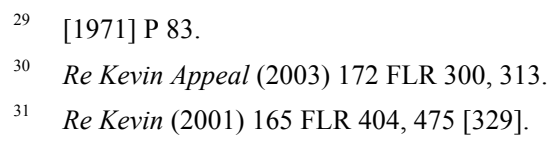


Family Court, who cited the reasons of Chisholm J extensively and agreed with his Honour's reasoning and conclusions. ${ }^{32}$

\section{GENDER IDENTIFICATION AT THE STATE LEVEL}

Legislative requirements for gender identification vary between the states and territories but can be divided into two broad categories: the biological approach based on surgical sex reassignment requirements in Queensland, Tasmania, Victoria, New South Wales, Northern Territory and the Australian Capital Territory; and the multifactorial approach taken in Western Australia and South Australia, which comprises biological, psychological and social considerations. Importantly, however, the legal sex identity of a transgender person can be challenged and may therefore be determined by the courts. The High Court case of $A B v$ Western Australia demonstrates that despite legislative efforts by each state and territory to bring some clarity and predictability to this area of law, courts still have an important role to play in drawing the 'sex line' ${ }^{33}$ by interpreting the applicable legislation.

In Queensland an application for a change of sex identification must be accompanied by statutory declarations from two doctors confirming that the applicant has undergone sexual reassignment surgery. ${ }^{34}$ The Act defines 'sexual reassignment surgery' as a 'surgical procedure involving the alteration of a person's reproductive organs. ${ }^{, 35}$ An almost identical approach is taken under legislation in New South Wales, Victoria and Tasmania, ${ }^{36}$ however, in contrast to the other jurisdictions, Victoria does not allow a sex change to be registered until the person is 18 years of age. ${ }^{37}$

A slightly different approach is taken in the Northern Territory and Australian Capital Territory. In the Northern Territory, the requirement to undergo sexual reassignment surgery still exists, but the evidence required to

32 Re Kevin Appeal (2003) 172 FLR 300, 304-5 [16], 364 [374]-[376] (Nicholson CJ, Ellis and Brown JJ).

33 This term is used by Laura Grenfell and Anne Hewitt in 'Gender Regulation: Restrictive, Facilitative or Transformative Laws?’ (2012) 34 Sydney Law Review 761: see particularly their discussion in the text at footnote 44 of the case of Bellinger $v$ Bellinger [2003] 2 AC 467, 480 (Lord Nicholls) and 482 (Lord Hope).

34 Births, Deaths and Marriages Registration Act 2003 (Qld) s 23(4)(b)(i).

35 Ibid sch 2 .

36 Births, Deaths and Marriages Registration Act 1995 (NSW); Births, Deaths and Marriages Registration Act 1996 (Vic); Births, Deaths and Marriages Registration Act 1999 (Tas).

37 Births, Deaths and Marriages Registration Act 1996 (Vic) s 30A(1)(a). 
support the application is less extensive than that required in other states. In the Northern Territory the legislation requires only 'prescribed evidence, if any, that verifies that the adult or child who is the subject of the certificate has undergone sexual reassignment surgery'. ${ }^{38}$ The evidence required in the Australian Capital Territory is similarly less extensive. All that is required is a statutory declaration by either a doctor or a psychologist that certifies that the person 'has received appropriate clinical treatment for alteration of the person's sex'. 39

In South Australia the Sexual Reassignment Act 1988 ('SR Act') establishes a 2-limbed test for sex identification. Under this statute, magistrates may issue a recognition certificate if they are satisfied that the person: ${ }^{40}$

(i) believes that his or her true sex is the sex to which the person has been reassigned; and

(ii) has adopted the lifestyle and has the sexual characteristics of a person of the sex to which the person has been reassigned; and

(iii) has received proper counselling in relation to his or her sexual identity.

Under the first limb, biological criteria with respect to sex are to be considered in accordance with psychological self-identification. The second limb emphasises the importance of social factors, based on both lifestyle and social recognition. The legislation in Western Australia mirrors the South Australian approach. ${ }^{41}$

The statute provides for the issuing of a recognition certificate under s 4, which 'identifies a person who has undergone a reassignment procedure as being of the sex to which the person has been reassigned'. A 'reassignment procedure' as defined in s 3 of the SR Act

means a medical or surgical procedure (or a combination of such procedures) to alter the genitals or other sexual characteristics of a person, identified by birth certificate as male or female, so that the person will be identified as a person of the opposite sex.

The SR Act allows for an individual to legally register a change of sex by making an application to the Magistrates Court under s 7 for the issuing of a recognition certificate. However, s 7(10) provides that 'a recognition certificate cannot be issued to a person who is married.' Where a recognition certificate has been issued, a person may then apply to the Principal Registrar

\footnotetext{
38 Births, Deaths and Marriages Registration Act 2005 (NT) s 28c(1)(a).

39 Births, Deaths and Marriages Registration Act 1997 (ACT) s 25(1)(a)(i).

40 Sexual Reassignment Act 1988 (SA) ss 7(8)(b)(i)-(ii).

${ }^{41}$ Gender Reassignment Act 2000 (WA) ss 15(1)(b)(i)-(ii).
} 
of Births, Deaths and Marriages to have their sex altered on their birth certificate. The Registrar is then required under s 9 of the SR Act to "make such other entries and alterations on any register or index kept by the Registrar as may be necessary in view of the reassignment'. This provision extends to the alteration of birth certificates.

While the alteration of birth certificates is a relatively simple process in South Australia, difficulties often arise in other jurisdictions where stricter requirements for the alteration of birth certificates are imposed. For example, in New South Wales a person may be identified as another sex only where they have undergone a sex affirmation procedure. The repercussions of these laws in relation to birth certificates are that an individual's birth certificate may be altered only once surgical requirements have been fulfilled. Thus in accordance with legislation in many of the state jurisdictions, a person's birth certificate will not reflect the gender that they identify as, nor the gender that is accepted at the federal level.

\section{GENDER IDENTIFICATION LAWS AND THE REPERCUSSIONS FOR TRANSGENDER PEOPLE}

\section{A Inconsistencies between State and Federal Laws}

Areas regulated by Commonwealth legislation also require that a court adhere to the principles of the Australian Guidelines that are informed by the multifactorial test, and so go beyond considering purely biological factors. A potential dilemma arises for individuals who are recognised as being a certain gender at the state or territory level (in light of the biological tests applicable in most Australian jurisdictions) but who are recognised as another gender at the federal level for the purposes of the Marriage Act 1961 (Cth) ('Marriage $A c t$ '). Unless these inconsistencies in gender identification tests are resolved, uncertainties in the law will continue to arise and the individuals concerned may be in a position where their cases are treated differently depending on whether they are being determined by Commonwealth or state authorities. However, this issue could be resolved by implementing uniform legislation across jurisdictions that establishes a clear set of criteria for determining the sex identity of a transgender person.

In 2014, the Sexual Reassignment (Recognition Certificates) Amendment Bill was brought before the South Australian Parliament by the Australian Greens MLA, Tammy Franks. The purpose was to remove section 7(10), which states that 'a recognition certificate cannot be issued to a person who is 
married' from the $S R$ Act. ${ }^{42}$ This provision forces a married transgender person who wishes to be recognised as their chosen gender to obtain a divorce as a precondition for applying for a recognition certificate in South Australia. However, given that marriage is within the domain of Commonwealth legislative power, the legal status of the marriage is not touched by state gender identification rules. Under the Marriage Act, it appears that a marriage will remain valid even if an individual undergoes an operation to become the same gender as their partner after the marriage has taken place. ${ }^{43}$ Thus at the Commonwealth level, a problem arises only where an individual has first undergone sexual reassignment surgery and who then wishes to marry an individual who is the same gender. However, South Australian legislation currently forbids a recognition certificate from being issued to a person who is already married, which means that a married transgender person is unable to gain legal recognition of their post-operative gender in this State. So, while the South Australian SR Act does not use the stricter biological tests imposed by other states and territories, and instead has adopted the multifactorial test used by the Commonwealth, this fact alone does not mean that inconsistencies with the Australian Guidelines will not arise.

Section 7(10) of the $S R$ Act creates a potential conflict. It leads to the position where a transgender person in South Australia may be recognised as 'male' for some purposes and as 'female' for others. For example, if a married transgender person subsequently affirms their chosen gender as being the same as their spouse's gender, this status will be recognised by the Australian Guidelines (even though the Marriage Act will not allow same sex persons to enter the state of matrimony). Critically, however, the individual concerned will not be able to obtain a Recognition Certificate in South Australia that accords with their affirmed gender.

It could also be argued that s 7(10) of the $S R$ Act, which refuses recognition to married persons, is inconsistent with the Family Law Act 1975 (Cth), under which a divorce can be issued only 'on the ground that the marriage has broken down irretrievably'. ${ }^{44}$ However, under the $S R$ Act, a recognition certificate may not be issued to an individual who is married. This compels affected couples to seek a divorce so that a certificate may be issued, even in circumstances where they are not separated and the marriage has not 'broken

42 This amendment to the $S R$ Act has not been passed.

43 In re Kevin (2001) 165 FLR 404, 406 [10], Chisholm J noted that if the parties were a man and woman 'at the time of the marriage' they would be titled to a declaration of validity.

44 Family Law Act 1975 (Cth) s 48(1). 
down irretrievably'. Furthermore, under the Commonwealth Marriage Act, a marriage will be valid where the parties to it were 'man and woman' at the time they entered the marriage. ${ }^{45}$

\section{B Potential Implications in Relation to Same-Sex Marriage}

The fact that a person may be classified as one gender in their own state and as another at the federal level has significant implications in relation to marriage. For example, a married biologically-born female who identifies as male and who has taken biological measures to transition into a male (such as undergoing hormone therapy and having their ovaries surgically removed), would be considered male at the federal level. Therefore if this person had been married to a man before undergoing the surgery, this marriage would appear to constitute a same-sex marriage, despite the fact that $\mathrm{s} 5$ of the Marriage Act defines 'marriage' as 'the union of a man and a woman'.

\section{The New Zealand Position - A Solution to the Dilemma?}

A potential solution to resolving the dilemma for transgender individuals is to adopt an approach based on the New Zealand position, which is outlined in Attorney-General $v$ Otahuhu Family Court. ${ }^{46}$ In this case, Ellis $\mathrm{J}$ had to determine the gender of a transman for the purposes of the New Zealand Marriage Act 1955. His Honour held that the individual was a male despite being legally born a female, and emphasised the policy benefits of recognising a transgender individual as their adopted sex. ${ }^{47}$ Despite the fact that the individual still had female genitals, his Honour found psychological self-identification ${ }^{48}$ and external appearance ${ }^{49}$ to be the most important factors in determining the gender of a transgender individual.

While the Australian common law approach encompasses a liberal interpretation of the test that should be applied in determining the identity of a transgender person, the New Zealand common law approach allows for even more flexibility in determining gender. The approach encompassed in Attorney-General $v$ Otahuhu Family Court $^{50}$ has no biological basis

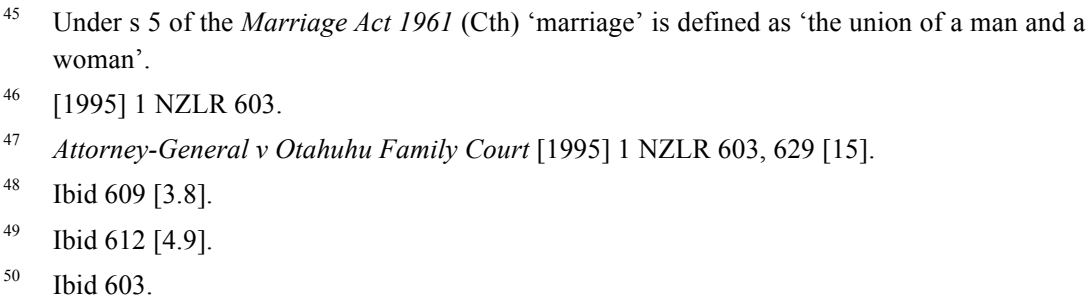


whatsoever, and is instead focused purely on psychological self-identification and the social perception of a transgender person in the general community.

In 2013 this dilemma was eliminated completely in New Zealand through the introduction of laws permitting same-sex marriages. Under the New Zealand Marriage Act 1955, marriage is now defined as 'a union of 2 people regardless of their sex, sexual orientation, or gender identity'. ${ }^{51}$ The significance of this definition is that it not only allows for homosexual couples to marry, but eliminates the need for a person to define themselves as either the same sex as their partner or as a different sex from their partner. Perhaps this is an opportune time for Australia to once again consider the broader debate revolving around same-sex marriage.

\section{CONCLUSION}

Australian jurisdictions should seek to amend their legislation so that a multifactorial approach to gender identification is adopted across all states and territories. Moreover, the states and territories should implement an approach consistent with the Commonwealth position, as encompassed in the Australian Government Sex and Gender Recognition Guidelines.

In addition to allowing more transgender individuals to be legally identified as their preferred sex, a clear definition of the attributes to be considered by courts in determining gender should be established. Such an outline would avoid uncertainties in the law from arising in the future. In relation to the issue of same-sex marriage specifically, adopting a uniform approach to gender identification across all levels of Australian governments would also resolve any inconsistencies that may arise in relation to marriage law. The adoption of a multifactorial approach to gender identification for the purposes of marriage law is supported by the authority of Re Kevin Appeal. ${ }^{52}$ Furthermore, by adopting the New Zealand approach which eliminates the significance of biological factors in determining a transgender person's sex identity for the purposes of marriage, the courts would be given even greater flexibility in determining gender.

\footnotetext{
Marriage Act 1955 (NZ) s 2(1).

52 (2003) 172 FLR 300.
} 